\title{
Formation of Silicide and Silicide-Aluminide Coatings on Molybdenum Alloy during Slurry Cementation Process: Influence of Slurry Volume
}

\author{
Agnieszka Elżbieta Kochmańska ${ }^{1, *(\mathbb{D})}$, Aneta Jarlaczyńska ${ }^{1}$ and Jolanta Baranowska ${ }^{1}$ (D) \\ Faculty of Mechanical Engineering and Mechatronics, West Pomeranian University of Technology in Szczecin, \\ Av. Piastow 17, 70-310 Szczecin, Poland; aneta.jarlaczynska@zut.edu.pl (A.J.); \\ Jolanta.Baranowska@zut.edu.pl (J.B.) \\ * Correspondence: agnieszka.kochmanska@zut.edu.pl
}

Citation: Kochmańska, A.E.; Jarlaczyńska, A.; Baranowska, J. Formation of Silicide and Silicide-Aluminide Coatings on Molybdenum Alloy during Slurry Cementation Process: Influence of Slurry Volume. Materials 2021, 14 6940. https://doi.org/10.3390/ ma14226940

Academic Editors: Filippo Berto, Abílio M. P. De Jesus and José A. F. O. Correia

Received: 26 October 2021 Accepted: 15 November 2021 Published: 17 November 2021

Publisher's Note: MDPI stays neutral with regard to jurisdictional claims in published maps and institutional affiliations.

Copyright: (c) 2021 by the authors. Licensee MDPI, Basel, Switzerland. This article is an open access article distributed under the terms and conditions of the Creative Commons Attribution (CC BY) license (https:// creativecommons.org/licenses/by/ $4.0 /)$.

\begin{abstract}
New slurry cementation method was used to produce silicide and silicide-aluminide protective coatings on molybdenum alloy (TZM). The slurry cementation processes were carried out at a temperature of $1000{ }^{\circ} \mathrm{C}$ in different time intervals with the use of varied slurry mass values. The microstructure and thickness of the coatings were studied by means of scanning microscopy. Chemical composition using X-ray microanalysis and phase composition using X-ray diffraction were also investigated. Coating microhardness was determined. The obtained coatings had a multilayer structure. Phases from the Al-Si-Mo system were observed in silicide-aluminide coatings and phases from the Si-Mo system were observed in silicide coatings. The microhardness strongly depended on the phase composition of the coating. It was demonstrated that slurry mass values had an important influence on the morphology and growth kinetics of silicide-aluminide coatings. In the case of a small amount of the slurry, the deficiency of alloying elements occurring during long processes reduces growth kinetics and can lead to void formation in the structure of silicide-aluminide coatings.
\end{abstract}

Keywords: slurry method; silicide coatings; aluminide coatings; molybdenum alloy

\section{Introduction}

Molybdenum alloy TZM is a promising structural material for the aerospace industry and nuclear or conventional power plant applications owing to its high creep and yield strength at elevated temperature, excellent corrosion resistance against irradiation embrittlement beyond $800{ }^{\circ} \mathrm{C}$, and good compatibility with alkali liquid metals [1]. In comparison with other metals used in these applications, such as titanium, niobium, molybdenum, tantalum, tungsten, and their alloys or creep-resistant steels and superalloys, TZM demonstrates the best combination of high allowed working temperature $\left(1700{ }^{\circ} \mathrm{C}\right)$ and density $\left(10.16 \mathrm{~g} / \mathrm{cm}^{3}\right)$. This material is the most suitable for use under high temperature and non-oxidizing conditions [1]. However, despite its high melting temperature and good mechanical properties, the use of TZM alloy at elevated temperature is limited by its poor resistance to oxidation. The $\mathrm{MoO}_{3}$ oxide that is formed on the TZM alloy surface in an oxidizing environment at $540{ }^{\circ} \mathrm{C}$ evaporates at $790{ }^{\circ} \mathrm{C}$ [2]. Therefore, at such temperatures, TZM alloy would have to be used in a controlled atmosphere such as vacuum or an inert gas, which is impractical in all the above-mentioned applications.

The formation of a protective coating on the alloy surface seems to be a good approach for improving the high temperature oxidation resistance of TZM alloy. An important requirement for such a coating is that it should ensure the formation of a self-healing protective oxide layer on the surface under working conditions, and in this way protect the TZM alloy against direct contact with atmospheric oxygen. Several coatings, mainly based on $\mathrm{Cr}, \mathrm{Ni}$, Au, B, Si, or Al, have already been studied to protect molybdenum alloys [3,4]. Of these, silicide coatings are considered to be the most attractive material for the protection 
of Mo and Mo-based alloys used in an oxidizing atmosphere at high temperature [3]. Such coatings usually contain the $\mathrm{MoSi}_{2}$ phase, which ensures the formation of a well-adherent and continuous $\mathrm{SiO}_{2}$ passive layer on the coated surface during high temperature oxidation. Furthermore, $\mathrm{MoSi}_{2}$ has a high melting temperature $\left(2030^{\circ} \mathrm{C}\right)$, excellent corrosion resistance at high temperature and moderate density $\left(6.31 \mathrm{~g} / \mathrm{cm}^{3}\right) . \mathrm{MoSi}_{2}$ is also considered as an attractive material for high-temperature structural applications at high temperature, because of its compatibility with many ceramic reinforcements. The main drawbacks of coatings containing $\mathrm{MoSi}_{2}$ phase include a brittleness at temperatures up to $1000{ }^{\circ} \mathrm{C}$ and a strong tendency to pesting within the temperature range of $300-600{ }^{\circ} \mathrm{C}$, due to the significant volume change of the $\mathrm{MoSi}_{2}$ phase (+85.5 vol.\%) during oxidation. The latter issue can be solved by the addition of aluminium to the coating. This results in a silicide-aluminide coating containing $\mathrm{Mo}(\mathrm{Si}, \mathrm{Al})_{2}$ phase, which demonstrates much smaller volume changes upon oxidation $(+4.9 \mathrm{vol} . \%)$. This phase is also very important from the viewpoint of resistance to high temperature oxidation, as it promotes the formation of a thin protective $\mathrm{Al}_{2} \mathrm{O}_{3}$ layer on the coating surface [5].

Several techniques, particularly pack cementation [5-8], chemical vapor deposition [9], electrodeposition [10], and hot dip plating [11] have been used for the manufacture of silicide coatings on molybdenum and TZM alloy. All of the coatings obtained by these methods consist of $\mathrm{MoSi}_{2}, \mathrm{Mo}_{5} \mathrm{Si}_{3}$, and $\mathrm{Mo}_{3} \mathrm{Si}$ sub-layers [5,12]. This means that all the phases that should be formed according to the Mo-Si diagram system are present [13]. Pack cementation is the most common method used for the manufacture of aluminide coatings $[14,15]$. There is only limited information available in the literature regarding silicide-aluminide coatings produced on TZM alloy [12] and it is reported that the coatings obtained consist of $\mathrm{Mo}(\mathrm{Si}, \mathrm{Al})_{2}, \mathrm{Mo}_{5}(\mathrm{Si}, \mathrm{Al})_{3}$, and $\mathrm{Mo}_{3}(\mathrm{Si}, \mathrm{Al})$ sub-layers $[13,16]$.

The powder mixture, which is used in the pack cementation method for the production of aluminide coatings, contains very fine aluminum and silicon powders (with typical size of a few micrometers), aluminum oxide powder as a filler, and halides powder as an activator. The presence of aluminum oxide significantly reduces the thermal conductivity of the mixture. For this reason, the coating process should be either conducted at high temperature-at least $1000^{\circ} \mathrm{C}$ or followed by an additional annealing at this temperature in order to obtain the desired coating composition and morphology [12]. The use of finegrained aluminum powder in this process creates the risk of explosion, which is why special safeguards in the production process are required $[6,12,17]$. Moreover, a large amount of chloride and hydrogen chloride is emitted in the pack cementation process, which makes this method environmentally harmful $[14,17]$. Aluminide coatings can also be obtained by chemical vapor deposition; however, this method is economically unfeasible [12].

Slurry methods are an interesting alternative to pack cementation and CVD processes. These technologies provide easy manufacturing of coatings on complex-shaped parts at low cost and slurries that can be used for this purpose are commercially available. However, the organic binder contained in these slurries means that an additional annealing step is needed in production, in order to expel the binder from the slurry before the main coating manufacturing process can be carried out [18-20].

A new technological approach is proposed in this paper. Our innovative method is based on a slurry in which the organic binder has been replaced by sodium silicate (water glass), which allows the production of coatings in a single technological step. The slurry after drying has a good mechanical durability due to the properties of water glass, which is important from the technological point of view. A workpiece with the dried slurry can be transferred to the furnace to create a coating without a risk of damage. The presence of water glass in the slurry and additionally silicon is also very important, since the curing of the slurry proceeds due to the dehydration of sodium silicate (water glass) in the presence of silicon. The use of silicon powder is therefore important from the technological point of view during the application of the slurry and during the formation of a diffusion coating (co-introduction silicon into aluminide). At the same time, dehydration of the aqueous sodium silicate solution in the presence of salts (which are also present in the slurry) leads 
to the formation of a spatial gel network. This promotes the formation of a slurry with a suitable consistency (gel) that facilitates application.

The usefulness of this method for the production of both silicide and silicide-aluminide coatings on molybdenum alloy has been confirmed in previous works [21-24]. This slurry method can be applicable for materials of a raw cast surface thanks to the presence of a flux in the slurry [21]. It is possible to produce aluminide coatings on titanium and nickel alloys $[23,24]$. It is also possible to produce a silicide coating on molybdenum alloy composed of three sub-layers with a phase composition according to the Mo-Si diagram system [22]. The silicide-aluminide layers produced by this method have a multi-layered morphology as with other methods, but the phases obtained are much richer in aluminum than those presented in the literature manufactured using other methods. Importantly, the critical $\mathrm{Mo}(\mathrm{Si}, \mathrm{Al})_{2}$ phase was present in all of the coatings obtained. The increased aluminum content measured in these phases can be beneficial from the viewpoint of corrosion resistance, ensuring sufficient aluminum supply during the self-healing process upon high temperature oxidation. The paper presents studies on the influence of the slurry volume used during the manufacturing process, on silicide and silicide-aluminide coating formation on TZM alloy.

\section{Materials and Methods}

Samples of dimensions $10 \times 6 \times 30 \mathrm{~mm}$ were prepared from TZM alloy containing approximately (\% wt.): $0.5 \% \mathrm{Ti}, 0.1 \% \mathrm{Zr}, 0.02 \% \mathrm{C}$ and Mo balance. The samples were mechanically grounded and cleaned in an acetone bath before being immersed in the slurry. Two types of slurries were prepared. The first slurry contained only silicon powder and the second a mixture of aluminum and silicon (with $\mathrm{Al} / \mathrm{Si}$ mass ratio 9:1); these being the active components of the slurry used to obtain silicide or silicide-aluminide coatings, respectively. The grain size of the powder used was approximately $100 \mu \mathrm{m}$ for aluminum and within the range 200-250 $\mu \mathrm{m}$ for silicon. The further composition of the slurries was the same for both processes, with an inorganic binder (an aqueous solution of sodium silicate) and a flux (a mixture of fused sodium and potassium salts: $\mathrm{NaF}, \mathrm{NaCl}$, and $\mathrm{KCl}$ ). The composition of the slurry was established experimentally. The ratio of the sodium silicate to powders of aluminum and silicon and the ratio of the salts to powders was 15/100 and 9.5/100, respectively.

The samples were immersed in the appropriate slurry and subsequently dried. The immersing and the drying operations were repeated several times where necessary until the slurry mass value achieved the appropriate amount. In the experiments three different quantities of slurries were applied: $0.15,0.3$, and $0.6 \mathrm{~g} / \mathrm{cm}^{2}$, corresponding to one, two or four immersion steps, respectively. The resulting values were calculated based on weight measurements of the samples.

The samples, covered with the slurry, were annealed in an argon atmosphere at $1000{ }^{\circ} \mathrm{C}$ for 2,4 , and $6 \mathrm{~h}$. After annealing, the slurry residues were mechanically removed, and the samples were washed in an ultrasonic bath in acetone. The residues easily detached from the surface after annealing.

The microstructure of the coatings was examined on cross-sections using field emission scanning electron microscopy (FE-SEM) - Hitachi SU-70 (Hitachi, Naka, Japan) with X-ray microanalysis energy dispersive spectrometry (EDS)—Thermo Scientific NORAN System 7 (Madison, WI, USA), acceleration voltage $15 \mathrm{kV}$. X-ray diffraction (XRD) phase analysis was performed using $\mathrm{Cu}-\mathrm{K} \alpha$, using $\mathrm{X}$-ray tube parameters of $35 \mathrm{kV}$ and $45 \mathrm{~mA}$ and a Bragg-Brentano geometry (X'Pert-PRO, Panalytical, Almelo, The Netherlands). The applied step of the goniometer was $0.05^{\circ}$, and the acquisition time was $200 \mathrm{~s}$. The acquired data were processed using $X^{\prime}$ Pert HighScore (v. 2.2.1) software provided by Panalytical. Microhardness tests were performed using a Buehler hardness tester MicroMet 2000 (Lake Bluff, IL, USA) with a Knoop indenter at a load of $0.098 \mathrm{~N}$ for $15 \mathrm{~s}$. Microhardness tests were conducted on cross-sections of the coatings. 


\section{Results \\ 3.1. General Coating Morphology}

As has been already mentioned, according to literature studies [5,6], silicide and silicide-aluminide coatings obtained on TZM alloys by the pack cementation method both consist of three sub-layers. Schematic representations of the coating morphology are presented in Figure 1a,b.

a)

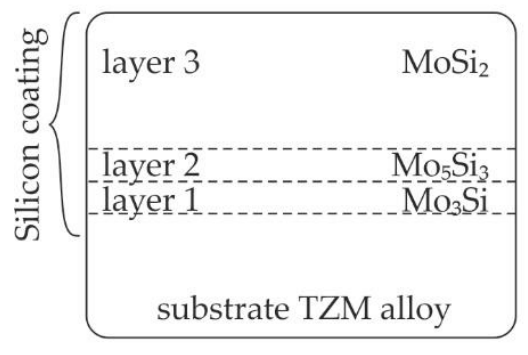

b)

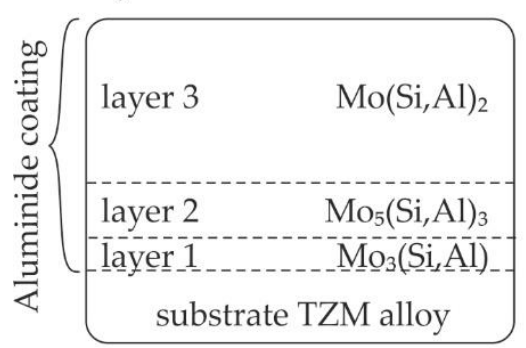

c)

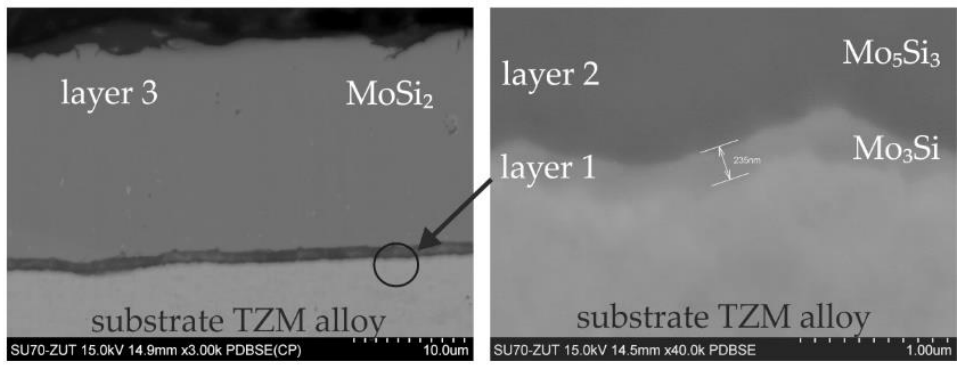

d)
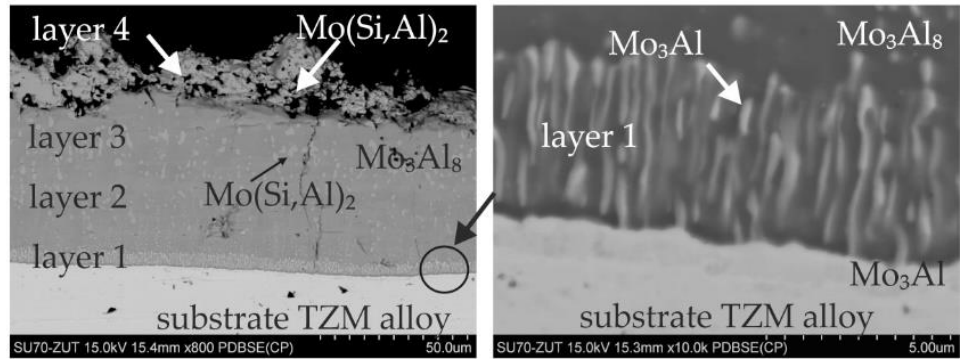

Figure 1. Graphical representation of (a) Si and (b) Si-Al coatings manufactured by the pack cementation method [5,6], and the microstructure of (c) Si coating and (d) Si-Al coating obtained by the slurry cementation process in the current studies $\left(2 \mathrm{~h}\right.$ at $1000{ }^{\circ} \mathrm{C}$, slurry volume of $\left.0.3 \mathrm{~g} / \mathrm{cm}^{2}\right)$.

It was demonstrated in our previous studies [22] that our method is able to produce silicide coatings composed of three sub-layers with the same phase composition as the coatings obtained by other methods. Figure 1c shows an example cross-section of such a coating. The external sub-layer 3 was composed of the $\mathrm{MoSi}_{2}$ phase, which is the richest in silicon and accounts for almost $90 \%$ of the coating volume. This is because of the growth rate, higher for the $\mathrm{MoSi}_{2}$ phase than for the $\mathrm{Mo}_{5} \mathrm{Si}_{3}$ phase forming sub-layer $2[25,26]$. The $\mathrm{Mo}_{3} \mathrm{Si}$ phase, which is the richest in molybdenum and was approximately $200-300 \mathrm{~nm}$ thick, was formed adjacent to the substrate.

The silicide-aluminide coatings produced by the pack cementation method are composed of $\mathrm{Mo}(\mathrm{Si}, \mathrm{Al})_{2}, \mathrm{Mo}_{5}(\mathrm{Si}, \mathrm{Al})_{3}$, and $\mathrm{Mo}_{3}(\mathrm{Si}, \mathrm{Al})$ sub-layers as schematically shown in Figure $1 \mathrm{~b}$ [5]. The silicide-aluminide layers produced by the method used in the current study also had a multi-layered morphology, but four sub-layers could be distinguished instead of the three observed in the coatings presented in the literature manufactured using the other method [5]. Importantly, the $\mathrm{Mo}(\mathrm{Si}, \mathrm{Al})_{2}$ phase- fourth sub-layer, critical from the corrosion resistance point of view, was present on the top of all the coatings obtained. Sub-layers 3 and 2 were mainly composed of $\mathrm{Mo}_{3} \mathrm{Al}_{8}$ phase (point 1 in Figure 2 and Table 1) and $\mathrm{MoAl}_{3}$ phase, respectively. Moreover, numerous large, spherical precipitates of $\mathrm{Mo}(\mathrm{Si}, \mathrm{Al})_{2}$ phase were spread throughout these sub-layers. Sub-layer 1 had a multiphase microstructure, i.e., elongated precipitates of $\mathrm{Mo}_{3}(\mathrm{Si}, \mathrm{Al})$ phase were uniformly distributed within a $\mathrm{Mo}_{3} \mathrm{Al}_{8}$ matrix (point 2 in Figure 2 and Table 1) and were oriented perpendicular to the sub-layer boundary. $\mathrm{Mo}_{3}(\mathrm{Si}, \mathrm{Al})$ phase also formed a continuous layer near to the substrate (point 3 in Figure 2 and Table 1). The sub-layers from 1 to 3 mostly contained 
$\mathrm{Al}$, Mo-based phases, and were much richer in aluminum than the corresponding phases observed in other coatings (Figure 1b). The increased aluminum content measured in these phases can be beneficial from the viewpoint of corrosion resistance, ensuring sufficient aluminum supply in a self-healing process upon high temperature oxidation [27].

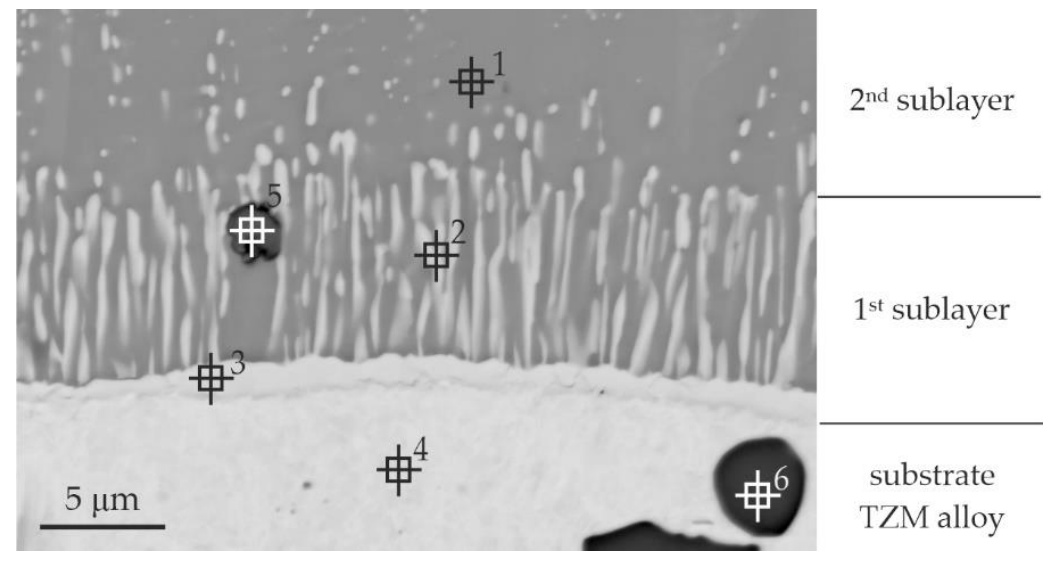

Figure 2. Microstructure (BEI) of a part of $\mathrm{Si}-\mathrm{Al}$ coating (from the second group of samples) obtained on TZM alloy at temperature $1000{ }^{\circ} \mathrm{C}$ in $6 \mathrm{~h}$ with a quantity of slurry $0.3 \mathrm{~g} / \mathrm{cm}^{2}$ with points of X-ray microanalysis.

Table 1. The results of the EDS point analysis of Si-Al coating according to Figure 2.

\begin{tabular}{cccccc}
\hline \multirow{2}{*}{ Point of Analysis } & \multicolumn{5}{c}{ Chemical Composition, \% at } \\
\cline { 2 - 6 } & $\mathbf{A l}$ & $\mathbf{S i}$ & $\mathbf{M o}$ & $\mathbf{T i}$ & $\mathbf{Z r}$ \\
\hline 1 & 70.3 & 0.7 & 29.0 & 0.0 & 0.0 \\
2 & 43.5 & 14.1 & 42.4 & 0.0 & 0.0 \\
3 & 19.7 & 6.5 & 73.8 & 0.0 & 0.0 \\
4 & 0.7 & 0.0 & 99.1 & 0.2 & 0.0 \\
5 & 3.1 & 0.1 & 0.3 & 94.9 & 1.6 \\
6 & 0.9 & 0.3 & 0.8 & 95.8 & 2.2 \\
\hline
\end{tabular}

Additionally, titanium and zirconium carbides, which may be present in the alloy structure, were observed (points 5, 6 in Figure 2 and Table 1). It should be emphasized here that these precipitations were observed not only in the substrate, but also in sub-layers located next to the substrate (sub-layer 1 and 2).

XRD phase analysis was performed on the surfaces of all the coatings. The phase composition of the silicide and silicide-aluminide coatings is shown in Figure 3. Because the results were very similar for each coating group, one representative diffractogram pattern of each group is presented.

In the case of the silicide coatings, a clear presence of the $\alpha-\mathrm{MoSi}_{2}$ phase was observed. In addition, weaker reflections from the $\mathrm{Mo}_{5} \mathrm{Si}_{3}$ and $\mathrm{Mo}_{3} \mathrm{Si}$ phases were also noticeable.

After analyzing the diffractogram pattern of the silicide-aluminide coatings, the phases $\mathrm{Mo}(\mathrm{Si}, \mathrm{Al})_{2}, \mathrm{Mo}_{3} \mathrm{Al}_{8}$, and $\mathrm{MoAl}_{3}$ were identified. Some differences were found in the diffraction patterns obtained for the silicide-aluminide coatings, mainly regarding the intensity of the $\mathrm{MoAl}_{3}$ and $\mathrm{Mo}_{3} \mathrm{Al}_{8}$ phase peaks (Figure 4). It was found that the peak intensity of the $\mathrm{MoAl}_{3}$ phase decreases as the annealing time is extended (Figure $4 \mathrm{~b}$ ). Conversely, the intensity of the $\mathrm{Mo}_{3} \mathrm{Al}_{8}$ phase peaks increases with increasing annealing time (Figure 4a). This is to be expected because of the extension of the annealing time effect on the diffusion of aluminum, and the formation of phases containing smaller amounts of aluminum. In addition, a shift to the right of the peaks from the molybdenum-aluminum phases was observed, which may be due to the additional silicon content in these phases. 


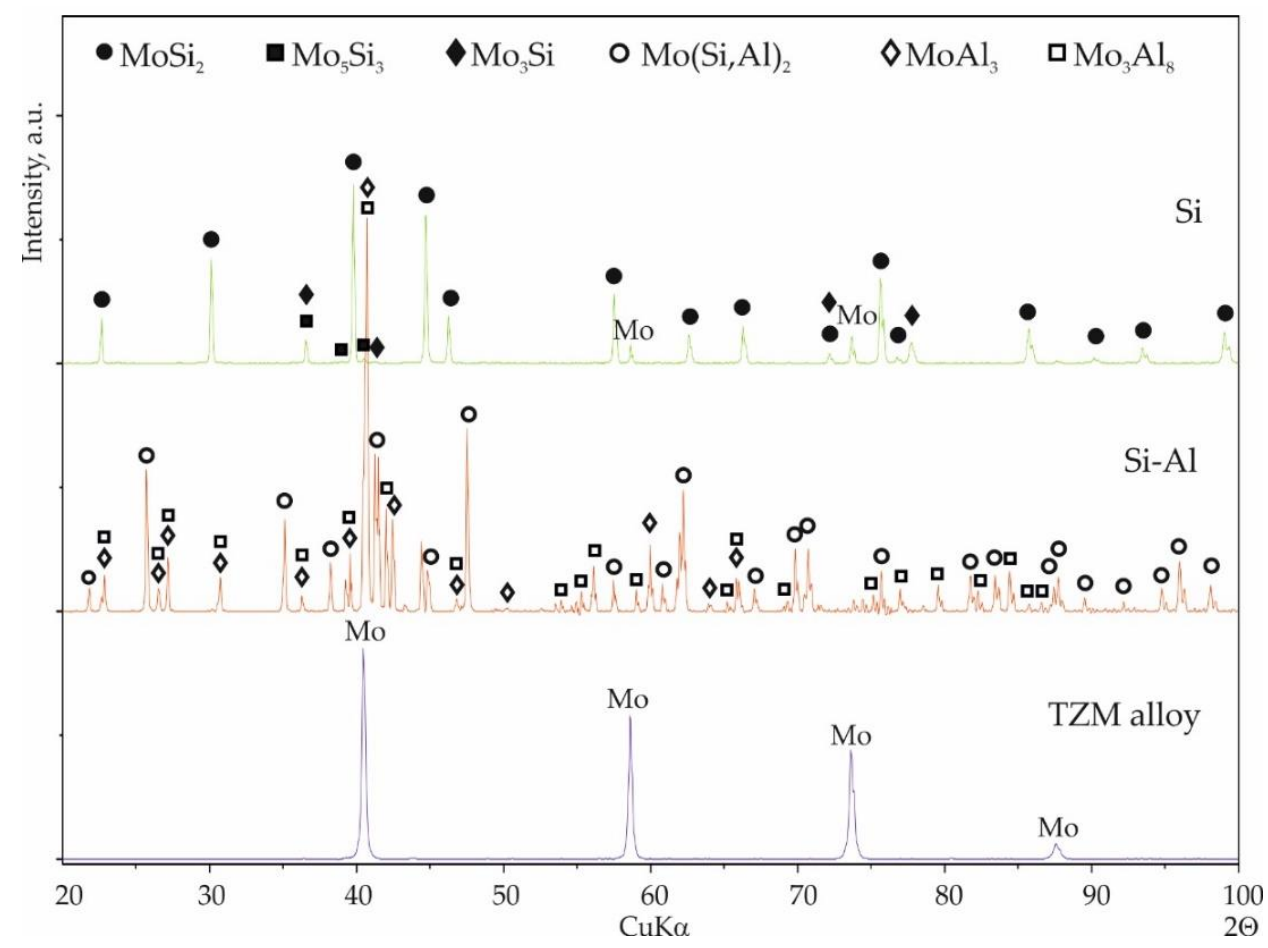

Figure 3. XRD patterns of $\mathrm{Si}$ and $\mathrm{Si}-\mathrm{Al}$ coating obtained on TZM alloy at temperature $1000{ }^{\circ} \mathrm{C}$ in $2 \mathrm{~h}$ with a quantity of slurry $0.3 \mathrm{~g} / \mathrm{cm}^{2}$.

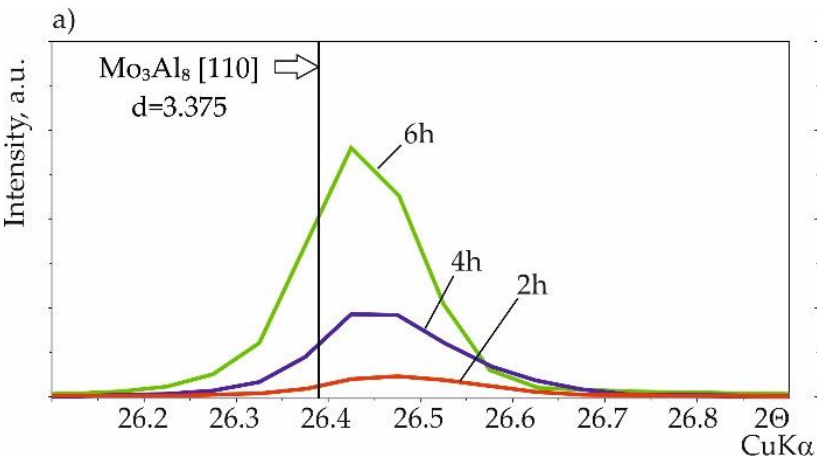

b)

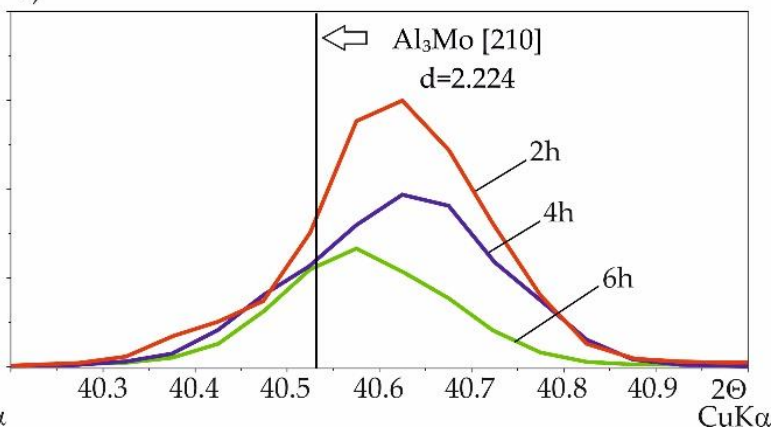

Figure 4. XRD pattern of Si-Al coating obtained on TZM alloy with a quantity of slurry $0.15 \mathrm{~g} / \mathrm{cm}^{2}$ at temperature $1000{ }^{\circ} \mathrm{C}$ in $2 \mathrm{~h}$ (red color), $4 \mathrm{~h}$ (blue color), $6 \mathrm{~h}$ (green color); (a) the part within the angle range from 26.1 to 26.9 ; (b) the part within the angle range from 40.2 to 41.0 .

\subsection{Influence of Slurry Volume on Coating Microstructure}

3.2.1. Silicide Coatings

Typical microstructures of the silicide coatings obtained for the different slurry volumes are presented in Figure 5. For slurry volumes of 0.15 and $0.3 \mathrm{~g} / \mathrm{cm}^{2}$ with annealing times of 4 or $6 \mathrm{~h}$, the third sub-layers described previously could be clearly distinguished, see Figure $5 \mathrm{a}, \mathrm{b}$. In the case of the coatings obtained with the highest slurry volume, the morphology was slightly different. The cross-sections showed that the bulk of the coating volume was composed of the $\mathrm{MoSi}_{2}$ phase (sub-layer 3 in Figure 5c). A thin sub-layer close to the substrate could be distinguished, but it was not possible to establish whether this thin sub-layer contained one or two phases. Only with the coatings obtained after annealing for $6 \mathrm{~h}$ was this sub-layer thick enough to carry out microanalysis (Figure 6), which revealed a decreased silicon content in this area (Table 2). However, an accurate phase analysis was not possible. It can be only hypothesized, that also $\mathrm{Mo}_{5} \mathrm{Si}_{3}$ and $\mathrm{Mo}_{3} \mathrm{Si}$ phases were formed in this area, according to the phase diagram $[9,26]$. There is a difficulty 
in observing and distinguishing between individual layers of coatings produced under certain conditions. If three silicide phases grow simultaneously, the coatings consisted of the $\mathrm{Mo}_{5} \mathrm{Si}_{3}$ phase always contain the $\mathrm{Mo}_{3} \mathrm{Si}$ phase as well.
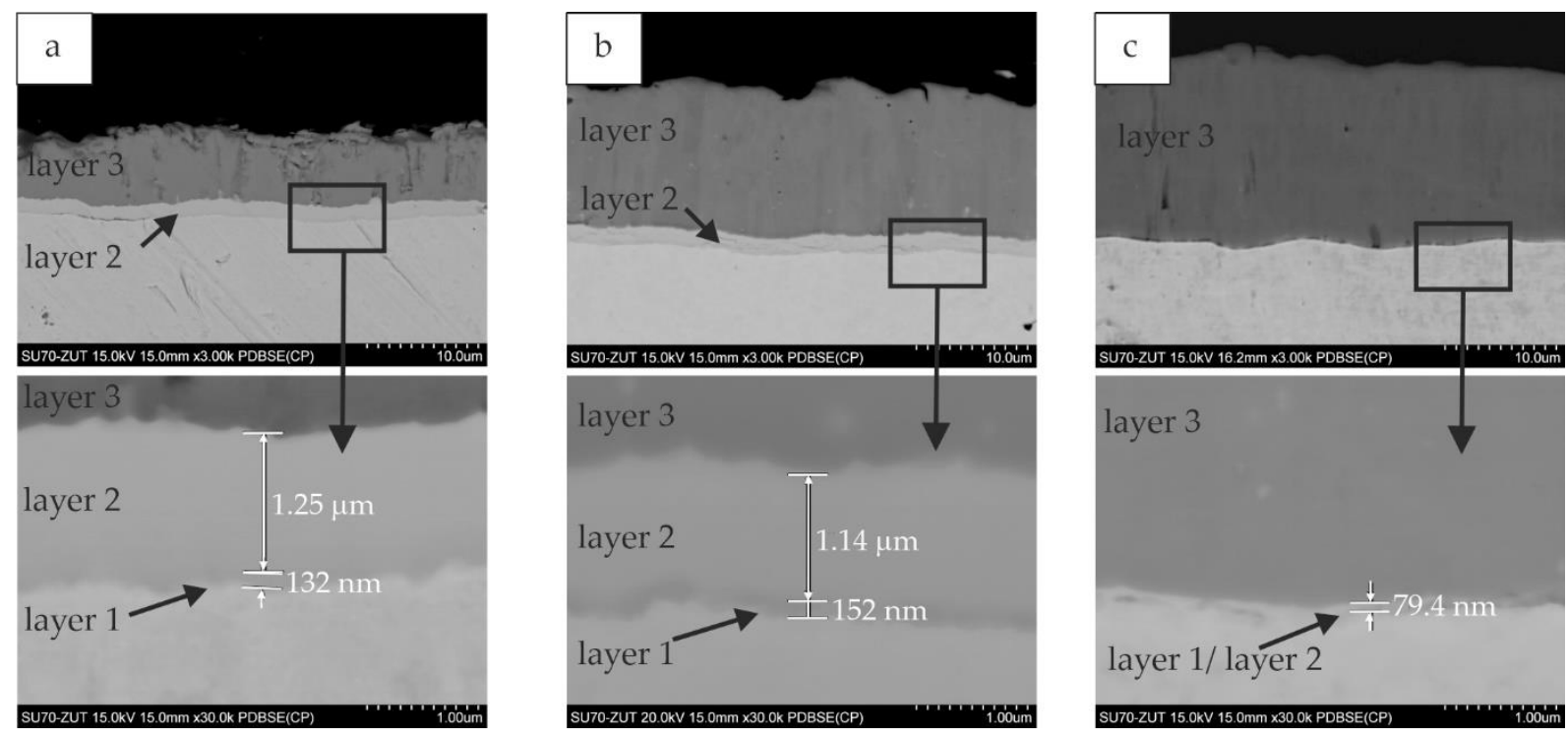

Figure 5. The microstructure (BEI) of Si coatings obtained at $100{ }^{\circ} \mathrm{C}$ for $4 \mathrm{~h}$ with the slurry volume of (a) 0.15 ; (b) 0.3 ; and (c) $0.6 \mathrm{~g} / \mathrm{cm}^{2}$.

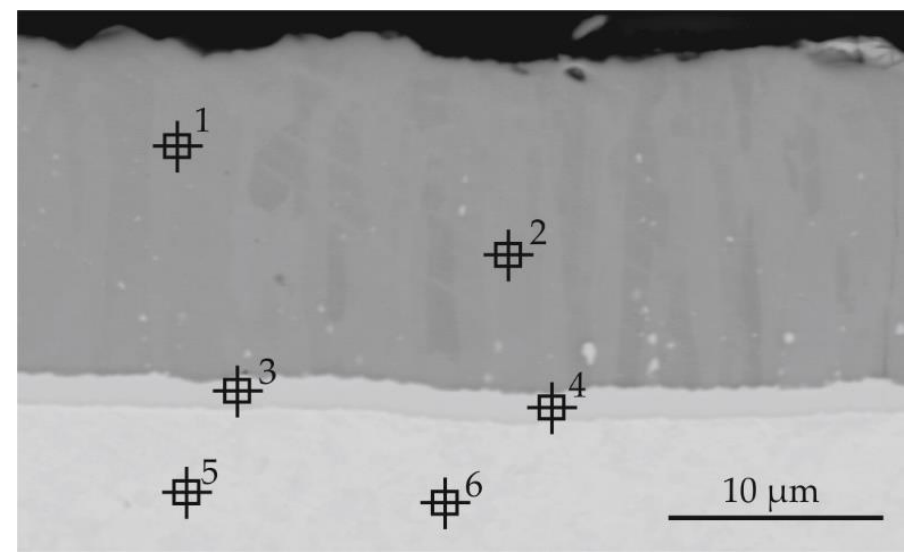

Figure 6. Microstructure (BEI) and point X-ray microanalysis is of Si coating obtained on TZM alloy for $6 \mathrm{~h}$ at $1000^{\circ} \mathrm{C}$ with the slurry volume of $0.3 \mathrm{~g} / \mathrm{cm}^{2}$.

Table 2. The results of the EDS point analysis of Si coating according to Figure 6.

\begin{tabular}{ccc}
\hline \multirow{2}{*}{ Point of Analysis } & \multicolumn{2}{c}{ Chemical Composition, $\%$ at } \\
\cline { 2 - 3 } & Si & Mo \\
\hline 1 & 65.2 & 34.8 \\
2 & 65.1 & 34.9 \\
3 & 45.5 & 54.5 \\
4 & 45.5 & 54.5 \\
5 & 0.0 & 100.0 \\
6 & 0.0 & 100.0 \\
\hline
\end{tabular}

The silicon atoms from the slurry are deposited onto the molybdenum alloy surface, where a chemical reaction occurs to form the $\mathrm{MoSi}_{2}$ phase. Over time, silicon is released by a decomposition reaction of the $\mathrm{MoSi}_{2}$ phase into the $\mathrm{Mo}_{5} \mathrm{Si}_{3}$ phase and silicon. This silicon diffuses into the substrate, and at the same time, molybdenum diffuses from the substrate 
towards the surface. However, silicon is the dominant diffusing element in all of the Mo-Si phases $\left(\mathrm{MoSi}_{2}, \mathrm{Mo}_{5} \mathrm{Si}_{3}\right.$ and $\left.\mathrm{Mo}_{3} \mathrm{Si}\right)$. The diffusion of silicon is appreciably larger than that of molybdenum in the $\mathrm{MoSi}_{2}$ phase and also larger in the $\mathrm{Mo}_{5} \mathrm{Si}_{3}$ and $\mathrm{Mo}_{3} \mathrm{Si}$ phases $[9,28]$. In the $\mathrm{MoSi}_{2}$ phase, Mo is practically immobile [28]. Thus, providing a large amount of silicon from the slurry causes a continuous increase in the $\mathrm{MoSi}_{2}$ layer, whilst if only a small amount of silicon is available in the slurry, this should result in the $\mathrm{Mo}_{5} \mathrm{Si}_{3}$ phase forming from the $\mathrm{MoSi}_{2}$ phase and further silicon diffusion inwards.

A smaller amount of silicon in the slurry and an extended process time may result in the appearance of Kirkendall voids [9,25,29], resulting from the different diffusion coefficients of silicon and molybdenum. The absence of Kirkendall voids in the present studies is observed. At this temperature $\left(1000^{\circ} \mathrm{C}\right)$, the amount of silicon from the slurry is expected to be sufficient to prevent the formation of Kirkendall voids. In previous work, Kirkendall voids were observed by the authors only in silicide coatings manufactured at $1200{ }^{\circ} \mathrm{C}$ [22]. Studies [30] have shown that, in well-annealed $\mathrm{MoSi}_{2}$, structural vacancies do not exist.

The $\mathrm{MoSi}_{2}$ layer has a columnar microstructure (Figure 6), with grains exhibiting a preferred direction of growth parallel to the diffusion direction $[6,9,12]$. The diffusion anisotropy in $\mathrm{MoSi}_{2}$ is a consequence of its tetragonal $\mathrm{C}_{1} 1_{\mathrm{b}}$ structure [31]. The diffusion coefficient of a tetragonal crystal, such as $\alpha-\mathrm{MoSi}_{2}$, has two principal componentsperpendicular and parallel to the tetragonal axis. The silicon diffusion perpendicular to the tetragonal axis is faster than parallel to it.

\subsubsection{Silicide-Aluminide Coatings}

The microstructure of the silicide-aluminide coatings was much more diverse than that of the silicide coatings and depended on the slurry volume used in the experiments. Example cross-sections are presented in Figure 7. All sub-layers 1-4 mentioned in Section 3.1 were identified in the coatings obtained with each slurry volume $\left(0.15,0.3\right.$, and $\left.0.6 \mathrm{~g} / \mathrm{cm}^{2}\right)$ used in the current study.
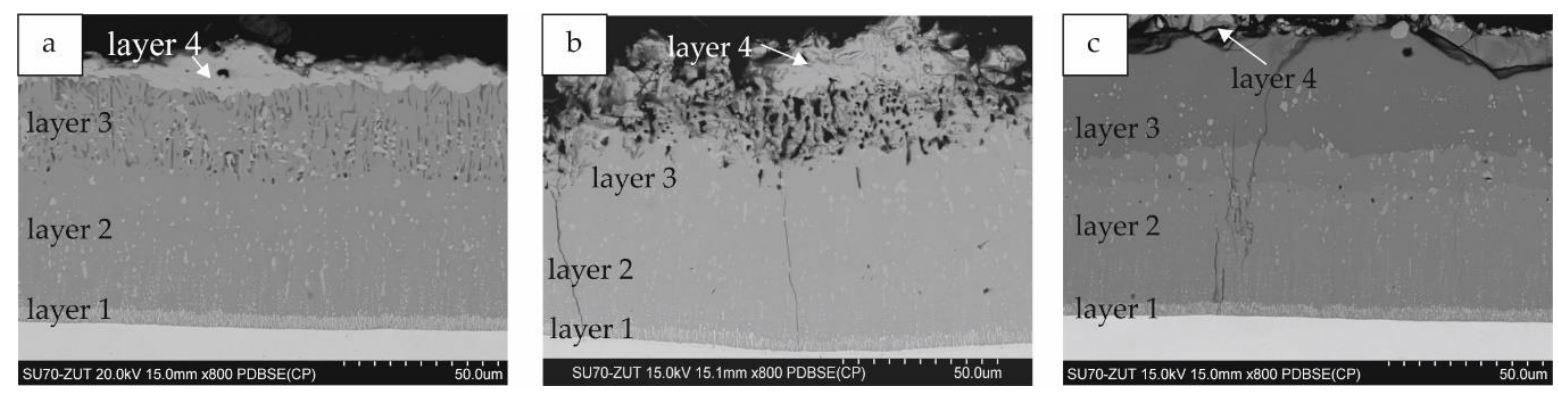

Figure 7. The microstructure (BEI) of Si-Al coatings obtained at $1000{ }^{\circ} \mathrm{C}$ for $4 \mathrm{~h}$ with the slurry volume of (a) 0.15 ; (b) 0.3 ; and $(\mathbf{c}) 0.6 \mathrm{~g} / \mathrm{cm}^{2}$.

The first layer closest to the substrate was characterized by the smallest thickness and a compact columnar structure. The second layer was characterized by a compact structure without voids with small precipitations throughout its cross-section. Sub-layer 3 was characterized by a certain porosity, and for some coatings, it had also higher aluminum content than sub-layer 2. The development of this sub-layer 3 was different depending on the time of annealing and the volume of the slurry used during the process.

Elemental maps for the coatings obtained with the smallest slurry volume after 2 and $4 \mathrm{~h}$ of annealing are presented in Figure 8. The coatings obtained after $6 \mathrm{~h}$ had the same elemental distribution as the coatings after $4 \mathrm{~h}$ of annealing. It can be observed that, after $2 \mathrm{~h}$, sub-layer 3 was richer in aluminum than sub-layer $2\left(\mathrm{MoAl}_{3}\right.$-Figure 8a, point 2, Table 3). Also, the silicon content was slightly higher in this sub-layer. After 4 and $6 \mathrm{~h}$ of annealing, the difference in aluminum content was insignificant; however, numerous voids were present in the area of sub-layer 3 . This is probably due to an insufficient supply of aluminum. The elemental maps for coatings obtained with 0.3 and $0.6 \mathrm{~g} / \mathrm{cm}^{2}$ of the slurry 
after $6 \mathrm{~h}$ are presented in Figure 9. For the coatings obtained with the highest slurry volume, a clear sub-layer 3 had already formed after $2 \mathrm{~h}$ of annealing and remained unchanged after $4 \mathrm{~h}$ (Figure 7c). This layer had a high porosity and a higher aluminum content than sub-layer 2. After $6 \mathrm{~h}$ of annealing, the porosity was not observable, but there was still an observable difference in aluminum content between these sub-layers (Figure 9b).
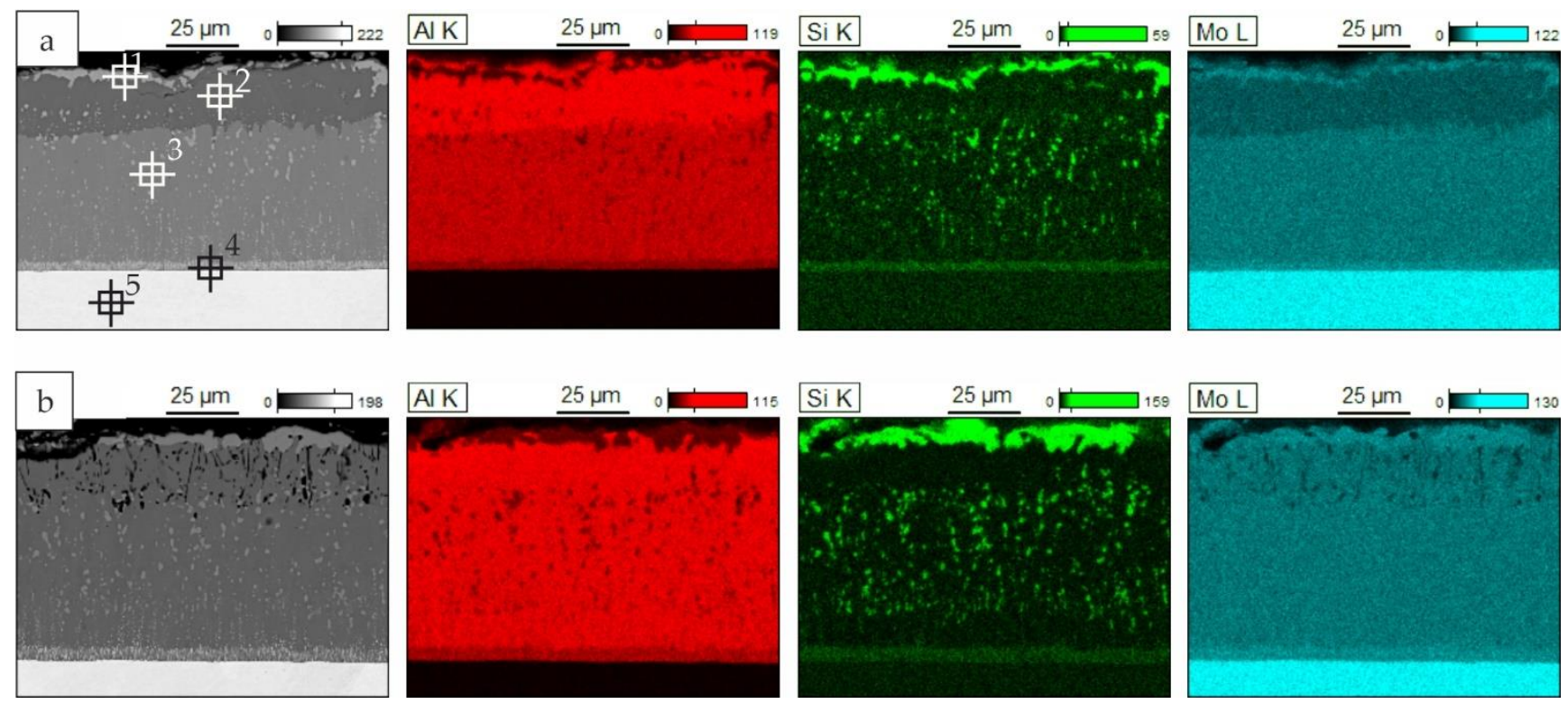

Figure 8. Elemental mapping (BEI/EDS) of cross-sections of Si-Al coatings obtained on TZM alloy at $1000{ }^{\circ} \mathrm{C}$ with the slurry volume of $0.15 \mathrm{~g} / \mathrm{cm}^{2}$ for (a) 2; (b) $4 \mathrm{~h}$ (with points of X-ray microanalysis).

Table 3. The results of the EDS point analysis of Si-Al coating according to Figure 8a.

\begin{tabular}{cccc}
\hline \multirow{2}{*}{ Point of Analysis } & \multicolumn{3}{c}{ Chemical Composition, \% at } \\
\cline { 2 - 4 } & Al & Si & Mo \\
\hline 1 & 23.1 & 42.4 & 34.5 \\
2 & 77.0 & 2.4 & 20.6 \\
3 & 70.3 & 1.1 & 28.6 \\
4 & 56.6 & 7.3 & 36.1 \\
5 & 0.8 & 0.0 & 99.2 \\
\hline
\end{tabular}

In general, the largest number of voids in layer 3 was observed with less slurry volume and longer time of annealing; in coatings prepared with 0.15 and 0.3 slurry after annealing for 4 and $6 \mathrm{~h}$ and for $6 \mathrm{~h}$, respectively.

The growth of the coatings by solid-state diffusion of $\mathrm{Al}$ and $\mathrm{Si}$ to the substrate could be dependent on the properties of these elements. The atomic size of silicon (1.32 $\AA$ ) is smaller than that of aluminum (1.43 $\AA$ ) [32]. Also, valence state of silicon (4) is higher than aluminum (3). This means that silicon should diffuse faster than aluminum. The atomic size of molybdenum is between that of aluminum and silicon and amounts to $1.39 \AA$. Diffusion rate is dependent on molecular size because larger molecules diffuse slower than smaller molecules. Because diffusion relies on movement and movement relies on the size of the molecule, there is a direct relationship between molecular size and diffusion rate. Larger molecules necessitate larger amounts of energy to engage in the same level of activity as smaller molecules. 

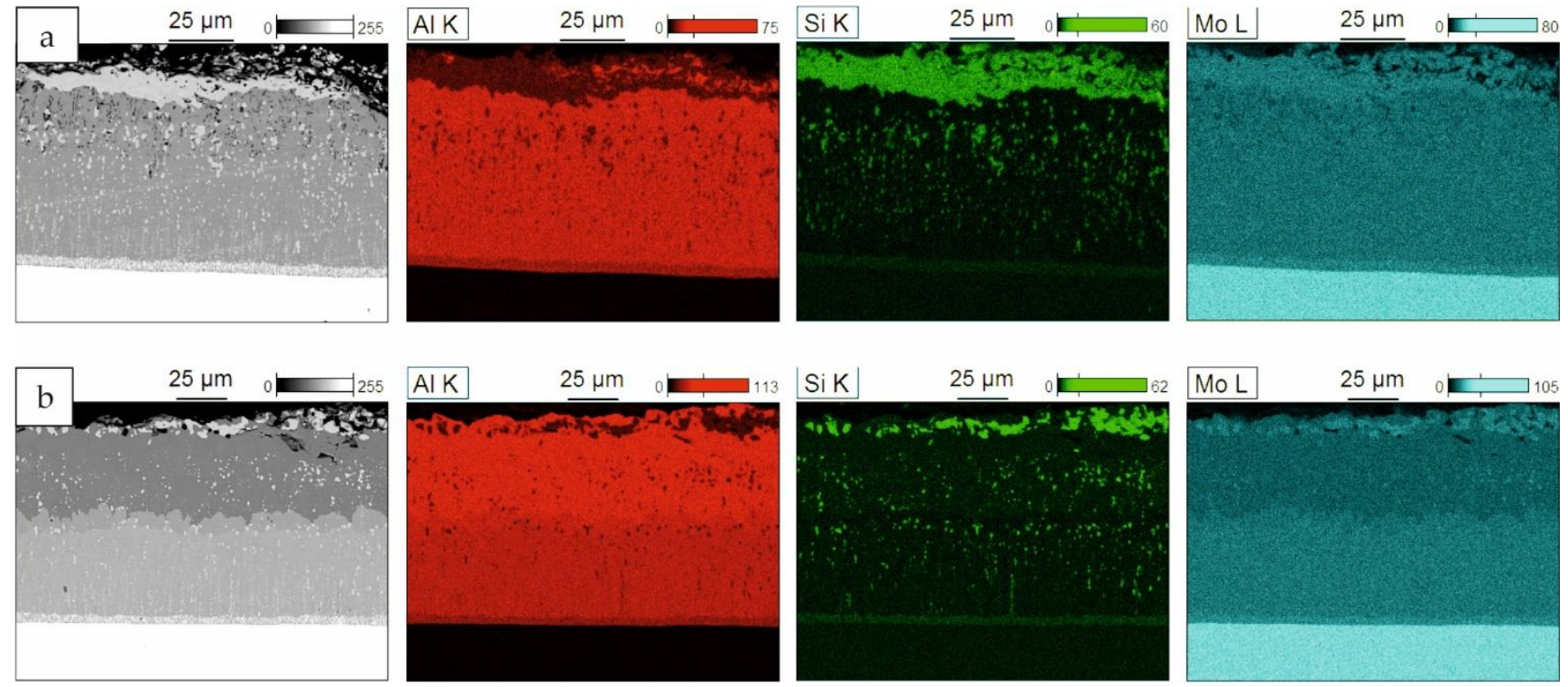

Figure 9. Elemental mapping (BEI/EDS) of cross-sections of Si-Al coatings obtained on TZM alloy at $1000{ }^{\circ} \mathrm{C}$ with the slurry volume of (a) $0.3 \mathrm{~g} / \mathrm{cm}^{2}$ and (b) $0.6 \mathrm{~g} / \mathrm{cm}^{2}$ for $6 \mathrm{~h}$.

Summarizing, for smaller slurry volume and longer annealing time, the formation of voids may be the result of a depletion of the elements from the slurry and a simultaneous inward diffusion of silicon. Increasing the slurry volume, even for a longer annealing time, reduces the formation of voids because the elements are still being supplied from the slurry.

\subsection{Influence of Slurry Volume on Coating Thickness}

\subsubsection{Silicide Coatings}

The thickness of the silicide coatings increased with annealing time (Figure 10). The total thickness of the coatings depended only on the thickness of sub-layer 3 . The growth of the silicon-rich sub-layer depended strongly on the slurry volume used in the experiments. The third layer obtained after $2 \mathrm{~h}$ of annealing with any slurry volume had a similar thickness. The thickness of the third layer was also similar for coatings manufactured with the $0.15 \mathrm{~g} / \mathrm{cm}^{2}$ slurry volume, even with the time extension. For slurry volumes of 0.3 and $0.6 \mathrm{~g} / \mathrm{cm}^{2}$, the third layer obtained after $4 \mathrm{~h}$ of annealing were similar, and $50 \%$ thicker than the third layer obtained with the smallest slurry volume. The provision of silicon over time increased the thickness of the $\mathrm{MoSi}_{2}$ sub-layer.

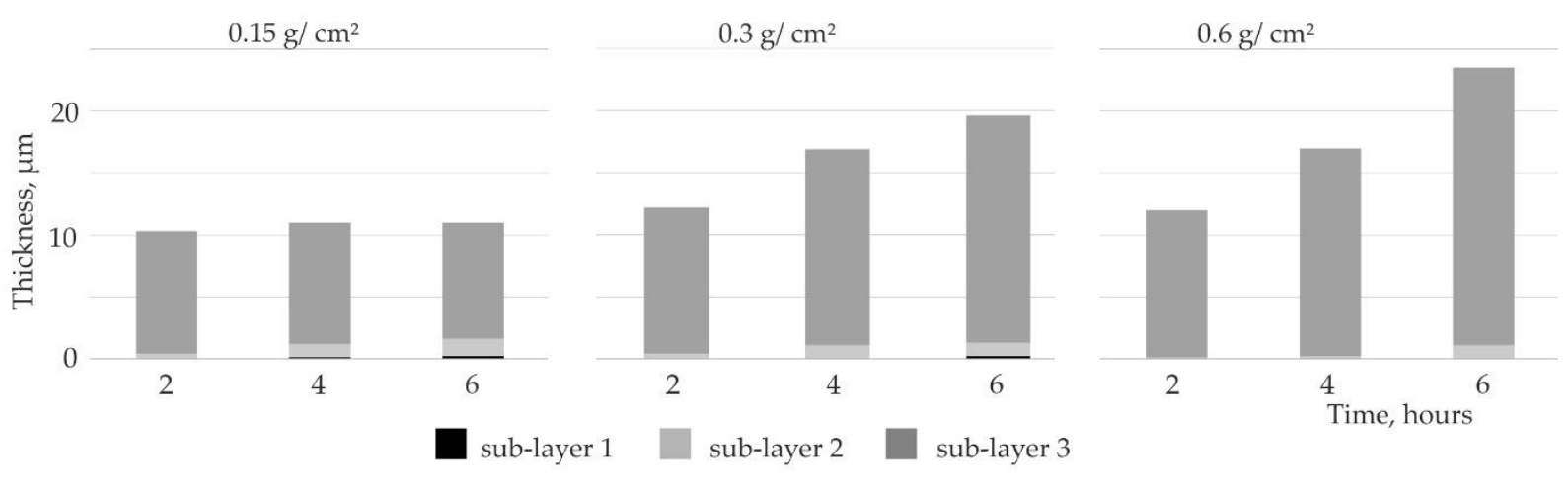

Figure 10. Thickness of Si coatings obtained at $1000^{\circ} \mathrm{C}$ for different slurry volume and after varied annealing times. 
The thicknesses of sub-layers 1 and 2 also changed depending on the time and the slurry volume. If the amount of silicon was limited (0.15), a more intensive growth of the $\mathrm{Mo}_{5} \mathrm{Si}_{3}$ sub-layer, followed by the $\mathrm{MoSi}_{3}$ sub-layer, was observed. This increase of the first and second layers was at the expense of the $\mathrm{MoSi}_{2}$ sub-layer.

The rate of silicon diffusion through the obtained silicide coating decreases as the $\mathrm{MoSi}_{2}$ sub-layer thickness increases. Further annealing leads to the simultaneous growth of both the $\mathrm{Mo}_{5} \mathrm{Si}_{3}$ and the $\mathrm{Mo}_{3} \mathrm{Si}$ sub-layers. This clearly indicates that the silicon supply was a factor limiting the coating growth.

\subsubsection{Silicide-Aluminide Coatings}

The thickness of the silicide-aluminide coatings was much larger than the silicide coatings obtained using the same process conditions (Figure 11). After $2 \mathrm{~h}$ of annealing, the thickness of all the coatings was similar (approximately $75 \mu \mathrm{m}$ ). Differences were observed after 4 or $6 \mathrm{~h}$ of annealing. The increases in coating thickness measured after 4 and $6 \mathrm{~h}$ of annealing were greater when the slurry volume was larger. It can be also observed that, in the case of the coatings obtained with the highest slurry volume, sub-layers 2 and 3 (composed of aluminum-rich phase) were the thickest. The thickness of the silicon-rich area (sub-layer 4) was comparable to the thickness of the silicide coatings (previously described in Section 3.3.1) obtained in comparable conditions with 0.15 and $0.3 \mathrm{~g} / \mathrm{cm}^{2}$ slurry (Figure 10).
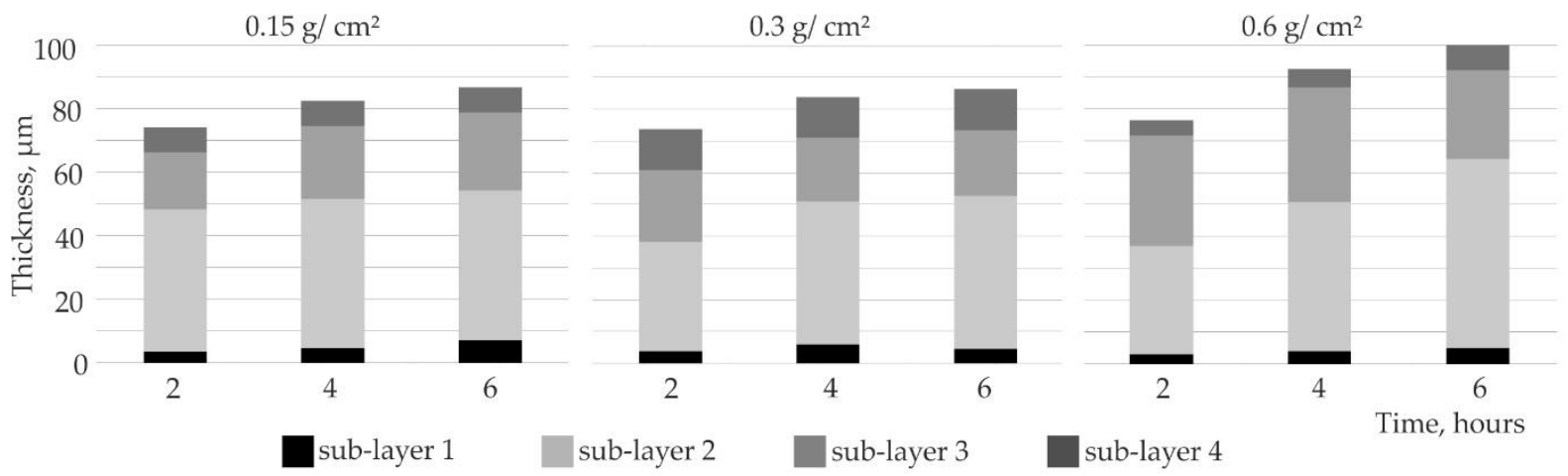

Figure 11. Thickness of Si-Al coatings obtained at $100{ }^{\circ} \mathrm{C}$ for different slurry volume and after varied annealing times.

The process of saturation with aluminum, or aluminum together with silicon, using slurries is a variant of the liquid-phase aluminizing method, where the applied layer of the slurry limits the liquid-phase volume. The results of saturation, that is, the aluminum content of the coating formed, silicon content, and, hence, hardness, ductility, and other parameters, depend on the thickness of the applied slurry layer, the ratio of aluminum and silicon contents in its active component, diffusion annealing temperature, and time [17]. The liquid phase on the saturated surface ensures favorable conditions for adsorption and diffusion processes. Therefore, the coatings formation from the liquid phase when aluminum is in the slurry causes the coatings to grow faster. On the other hand, the liquid state is not obligatory for diffusion coating formation. A diffusion coating may form at saturation from the solid phase as well. In this case the process is more favorable for the formation of intermetallic phases with high heat of formation. Silicide coatings formed without aluminum in the slurry grow from the solid phase Therefore, the thickness of the silicide-aluminide coatings is larger than silicide coatings.

\subsection{Structure and Growth Model of Coatings}

The silicide-aluminide coatings were characterized by a more complex structure than the silicide ones. For this reason, a structure diagram of the coatings is presented in Figure 12. 
a) $0.15 \mathrm{~g} / \mathrm{cm}^{2} \quad 0.3 \mathrm{~g} / \mathrm{cm}^{2} \quad 0.6 \mathrm{~g} / \mathrm{cm}^{2}$

$2 \mathrm{~h}$
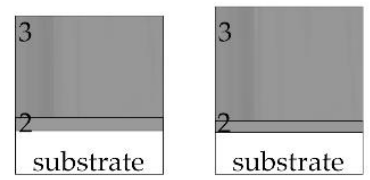

$\mathrm{h}$
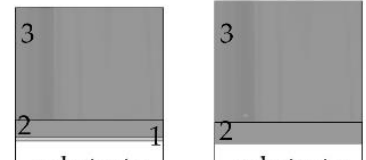

substrate

$6 \mathrm{~h}$
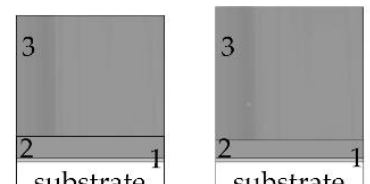

substrate
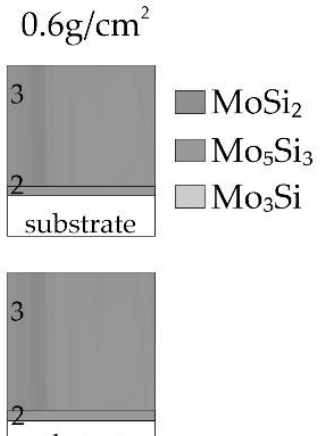

substrate

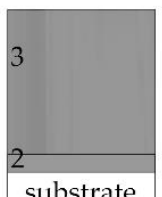

b)

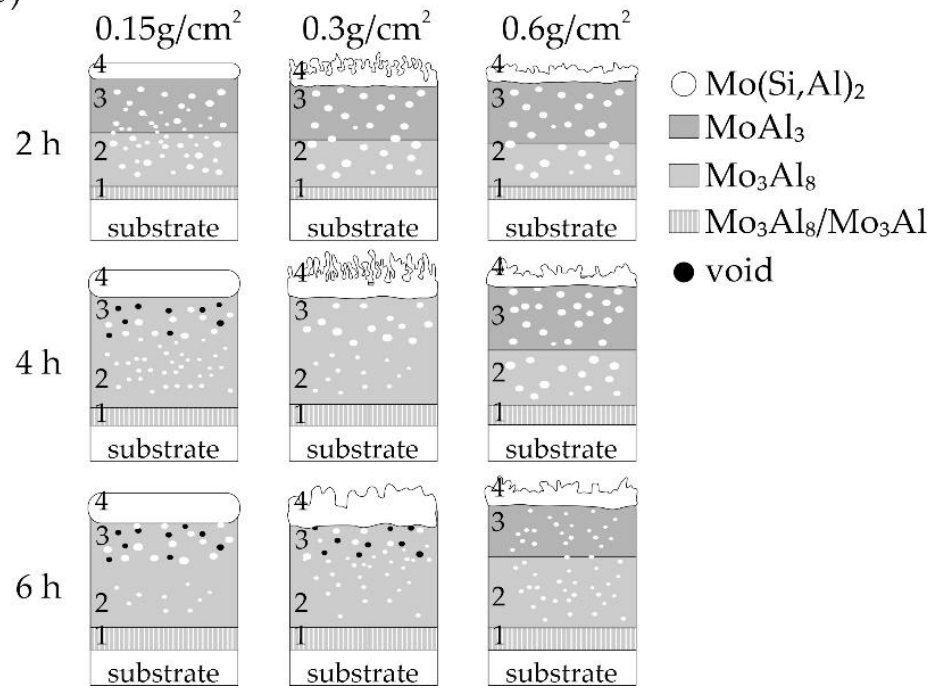

Figure 12. The scheme of the structure of (a) Si and (b) Si-Al coatings obtained on TZM alloy at $1000{ }^{\circ} \mathrm{C}$ for different slurry volume and different time.

In the case of the silicide coatings, it should be emphasized that they all are very similar in structure (Figure 12a). The outer columnar-structure sub-layer containing the $\mathrm{MoSi}_{2}$ phase was dominant in all of these coatings. Coatings produced in $2 \mathrm{~h}$ had the same structure, and their thickness increased slightly with increasing volume of the slurry. In coatings produced using a smaller volume of the slurry $(0.15$ and 0.3$)$, a prolonged annealing time resulted in an increase in the Si-poor first sublayer containing the $\mathrm{Mo}_{3} \mathrm{Si}$ phase.

In the case of the $\mathrm{Si}-\mathrm{Al}$ coatings, the coating structure observed after annealing for $2 \mathrm{~h}$ was similar, regardless of the slurry volume (Figure $12 \mathrm{~b}$ ). Individual sub-layers were different only in thickness (Figure 11). For small volumes of the slurry $\left(0.15\right.$ and $\left.0.3 \mathrm{~g} / \mathrm{cm}^{2}\right)$, an increase in the annealing time caused the $\mathrm{MoAl}_{3}$ phase, rich in aluminum, to not occur in the third sub-layer. At the same time, voids were formed in this sublayer. The presence of the $\mathrm{Mo}(\mathrm{Si}, \mathrm{Al})_{2}$ phase in all coatings was also observed. This phase is of particular importance from the point of view of oxidation stability. In some coatings, the sublayer containing this $\mathrm{Mo}(\mathrm{Si}, \mathrm{Al})_{2}$ phase was thin $\left(0.15 \mathrm{~g} / \mathrm{cm}^{2}\right)$ or partially porous $(0.3$ and $\left.0.6 \mathrm{~g} / \mathrm{cm}^{2}\right)$. However, oxidation tests are needed in order to verify the high-temperature resistance of the coatings.

Some similarities were observed between the two groups of coatings, both silicide and silicide-aluminide. Coatings produced using the $0.15 \mathrm{~g} / \mathrm{cm}^{2}$ slurry volume in 4 and $6 \mathrm{~h}$ and the $0.3 \mathrm{~g} / \mathrm{cm}^{2}$ slurry volume in $6 \mathrm{~h}$ were very similar for each group of coatings. In addition, the coatings produced in $2 \mathrm{~h}$ and using the $0.6 \mathrm{~g} / \mathrm{cm}^{2}$ slurry volume were also very similar within a given group of coatings.

Additionally, the relations between variable parameters and the thickness of the silicide (1) and silicide-aluminide (2) coatings were determined using Statistica 13 software. The multiple linear regression was used as an approach to modelling the relationship between a dependent variable (the thickness of coatings) and an independent variables (the slurry amount and the time of annealing). The equations thus obtained are presented below. The following notation was used: $\mathrm{Y}_{\mathrm{Si}}$ - the thickness of the silicide coatings $(\mu \mathrm{m}) ; \mathrm{Y}_{\mathrm{SiAl}}$ the thickness of the silicide-aluminide coatings $(\mu \mathrm{m}) ; X_{1}$-the slurry volume $\left(\mathrm{g} / \mathrm{cm}^{2}\right)$; $\mathrm{X}_{2}$-the annealing time (h).

$$
\begin{gathered}
Y_{S i}=5.7+15.1 \cdot X_{1}^{2}+1.7 \cdot X_{2} ; R=0.80 ; R^{2}=0.84 ; F=5.2 \\
Y_{S i A l}=60.3+35.7 \cdot X_{1}^{2}+4.8 \cdot X_{2} ; R=0.91 ; R^{2}=0.84 ; F=16.3
\end{gathered}
$$


The obtained equations indicate the thickness of the coatings produced at the temperature of $1000{ }^{\circ} \mathrm{C}$ depends quadratically on the slurry volume parameter and linearly on the time parameter, respectively. The goodness of fit of the obtained models is better for silicon-aluminide coatings (2) than for silicide coatings (1). Graphical representations of the Equations (1) and (2) are shown in Figure 13.

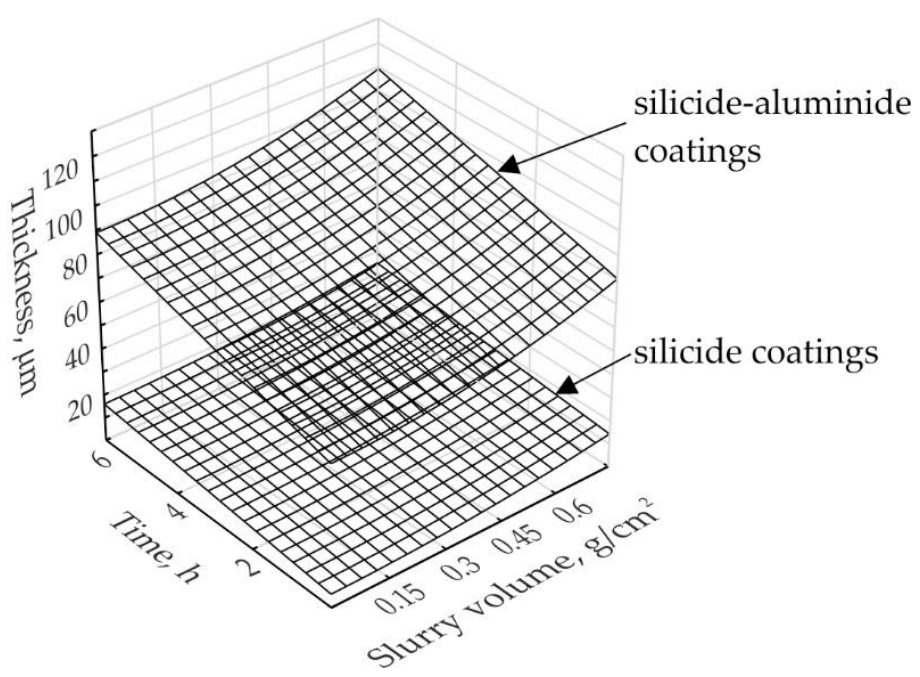

Figure 13. Graphical representation of the correlation between technological parameters and the coatings thickness obtained on TZM alloy at $1000^{\circ} \mathrm{C}$.

\subsection{Microhardness of Coatings}

Knoop hardness measurements were performed in layers 3 and in layers 3 and 2 for silicide coatings and silicide-aluminide coatings, respectively. Due to the low thickness of the remaining sub-layers, it was not possible to carry out microhardness measurements in these small sub-layers. Additionally, the base material of each sample was also investigated. The figure below (Figure 14) shows the results of microhardness tests for the silicide coatings obtained with the slurry of $0.3 \mathrm{~g} / \mathrm{cm}^{2}$, and silicide-aluminide coatings with extreme amounts of the slurry 0.15 and $0.6 \mathrm{~g} / \mathrm{cm}^{2}$.

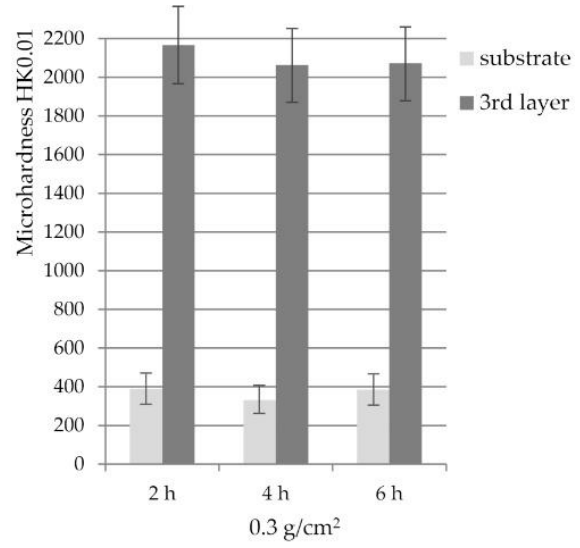

(a)

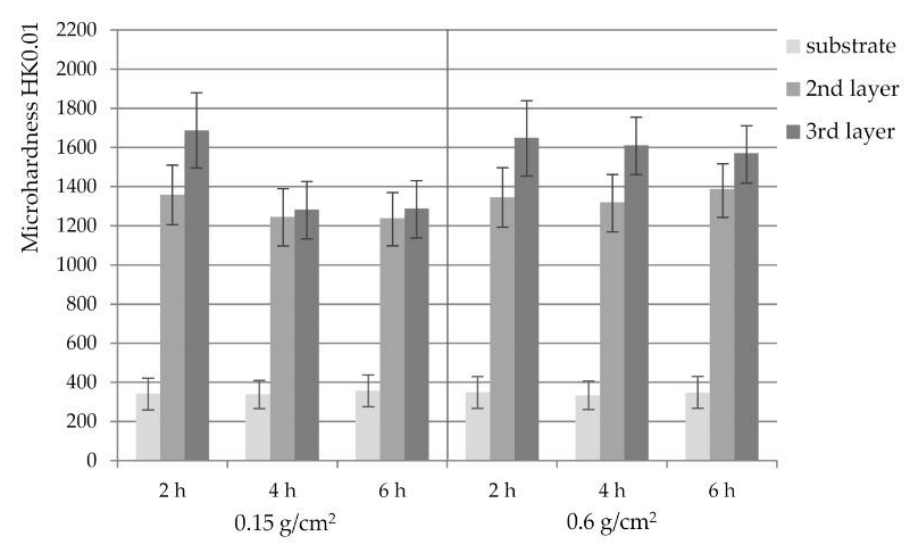

(b)

Figure 14. The results of the (a) Si and (b) Si-Al coating hardness measurements obtained on TZM alloy at $1000{ }^{\circ} \mathrm{C}$ for 0.15 and $0.6 \mathrm{~g} / \mathrm{cm}^{2}$ slurry volume and different time.

The microhardness of the external third layer of the silicide coatings (Figure 14a) was about $2100 \mathrm{HK} 0.01$, higher than that of the silicide-aluminide external third layer. The results of the coating microhardness measurements of the silicide coatings were very 
similar for each coating annealing time due to the same crystalline structure. The average for all silicide coatings was 2096 and 366 for the third layer and substrate, respectively. The standard deviation was 202 and 40 for the above measurements, respectively. The results show that the obtained silicide coatings are very hard and there is a large difference in hardness between the substrate and the coating. This can be the cause of possible cracks during operation, despite the fact that they are diffusion coatings.

In the case of the silicide-aluminide coatings, the microhardness test results (Figure 14b) correspond to the observations of the coating structure. They can be compared with the results shown in Figure 12b. The hardness of the sublayer 3 containing the $\mathrm{MoAl}_{3}$ phase is about $1600 \mathrm{HK} 0.01$. This hardness is higher than sublayer 2, containing the $\mathrm{Mo}_{3} \mathrm{Al}_{8}$ phase, which is about $1300 \mathrm{HK} 0.01$. The difference in hardness between sub-layers 2 and 3 is about 300 HK0.01.

Similar hardness values (approx. 1300 HK0.01) were observed for layers 2 and 3 in coatings produced for 4 and $6 \mathrm{~h}$ using $0.15 \mathrm{~g} / \mathrm{cm}^{2}$ of the slurry. The composition of these sub-layers is similar. They contain the $\mathrm{Mo}_{3} \mathrm{Al}_{8}$ phase, which is also shown in Figure $12 \mathrm{~b}$.

The resulting coatings with a gradient multi-layer structure were obtained because the aluminum forms several molybdenum aluminides. Each layer of coating contains a different phase component and represents other properties. The gradient of coatings is particularly advantageous in the context of aluminum content. If the aluminum content is greatest in the outer layer, this would promote increased resistance to oxidation or generally high temperature corrosion. Simultaneously, the highest aluminum content decreases the ductility and increases the hardness. Reducing the amount of aluminum in a layer closer to the substrate increases the ductility (decreases the hardness) of the coatings, which reduces the stresses that generate cracks.

\section{Conclusions}

It was demonstrated that the slurry cementation method based on inorganic binder is an effective way to produce both the silicide and the silicide-aluminide coating on molybdenum alloy. There is the ability to easily mix aluminum with other elements (in this study is silicon) that co-spend in the process of coating formation. Compared to other methods, the slurry method is a promising way of producing of the diffusion coatings.

It was also proven that the slurry volume applied during the slurry cementation of TZM alloy has an important influence on the morphology and growth kinetics of silicide and silicide-aluminide coatings.

The thickness of the sub-layers of the coating can be readily modified by changing the annealing time and the slurry volume. These parameters have a decisive influence on the coating morphology and composition, especially in the case of the silicide-aluminide coatings. Generally, all produced coatings were characterized by a multi-layer structure, silicide coatings - a three-layer structure, and silicide-aluminide coatings-a four-layer structure. The thickness of silicide-aluminide coatings is up to ten times greater than that of silicide coatings produced under the same conditions.

In the case of silicide coatings, it can be stated that:

- the main part of the coating is the outer sublayer containing the $\mathrm{MoSi}_{2}$ phase,

- the use of a small volume of the slurry $\left(0.15 \mathrm{~g} / \mathrm{cm}^{2}\right)$ during production and extension of the annealing time, did not significantly increase the thickness of the coatings, which was about $11 \mu \mathrm{m}$. In such conditions, increasing deficiency of the alloying elements slows down the kinetics of the Si-rich layer growth,

- the use of a larger volume of the slurry (0.3 and 0.6) during production and extension of the annealing time, significantly increased the thickness of the coatings, from about $12 \mu \mathrm{m}$ in the case of $2 \mathrm{~h}$ to about $20 \mu \mathrm{m}$ in the case of $6 \mathrm{~h}$ of annealing,

- the hardness of the coatings is similar, around $2100 \mathrm{HK} 0.01$, since all the resulting coatings contain the $\mathrm{MoSi}_{2}$ phase.

In the case of silicide-aluminide coatings, the following conclusions can be made: 
- the main components of the coatings were the two phases $\mathrm{MoAl}_{3}$ and $\mathrm{Mo}_{3} \mathrm{Al}_{8}$, while the outer sublayer contained the $\mathrm{Mo}(\mathrm{Si}, \mathrm{Al})_{2}$ phase, which should constitute a corrosion barrier,

- the use of a small volume of the slurry $\left(0.15 \mathrm{~g} / \mathrm{cm}^{2}\right)$ during production and extension of the annealing time resulted in the formation of voids in the cross-section of the coatings, moreover, the formation of phases with lower aluminum content is observed.

- the coating growth kinetics for 0.15 and 0.3 slurry volumes were similar. The thickness of the coatings produced for 2,4 , and $6 \mathrm{~h}$ was on average $75,82,85 \mu \mathrm{m}$, respectively,

- the use of a larger volume of the slurry (0.6) during production and extension of the annealing time, significantly increased the thickness of the coatings, from about $75 \mu \mathrm{m}$ in the case of $2 \mathrm{~h}$ to about $100 \mu \mathrm{m}$ in the case of $6 \mathrm{~h}$ of annealing,

- the hardness of the sublayers increased with increasing aluminum content and ranged from about 1200 to 1700 HK0.01.

Author Contributions: Conceptualization, A.E.K. and A.J.; Methodology, A.E.K. and A.J.; Investigation, A.E.K. and A.J.; Data curation, A.E.K. and A.J.; Writing—original draft preparation, A.E.K., A.J., and. J.B.; Writing-review and editing, A.E.K., A.J., and. J.B.; Visualization, A.E.K.; Supervision, A.E.K. All authors have read and agreed to the published version of the manuscript.

Funding: This research received no external funding.

Institutional Review Board Statement: Not applicable.

Informed Consent Statement: Not applicable.

Data Availability Statement: Data are contained within the article.

Conflicts of Interest: The authors declare no conflict of interest.

\section{References}

1. El-Genk, M.S.; Tournier, J.M. A review of refractory metal alloys and mechanically alloyed-oxide dispersion strengthened steels for space nuclear power systems. J. Nucl. Mater. 2005, 340, 93-112. [CrossRef]

2. Smolik, G.R.; Petti, D.A.; Schuetz, S.T. Oxidation and volatilization of TZM alloy in air. J. Nucl. Mater. 2000, $283,1458-1462$. [CrossRef]

3. Alam, M.Z.; Venkataraman, B.; Sarma, B.; Das, D.K. MoSi 2 coating on Mo substrate for short-term oxidation protection in air. J. Alloy. Compd. 2009, 487, 335-340. [CrossRef]

4. Yavas, B.; Goller, G. A novel approach to boriding of TZM by spark plasma sintering method. Int. J. Refract. Met. Hard Mater. 2019, 78, 273-281. [CrossRef]

5. Majumdar, S.; Sharma, I.G. Oxidation behavior of $\mathrm{MoSi}_{2}$ and $\mathrm{Mo}(\mathrm{Si}, \mathrm{Al})_{2}$ coated Mo-0.5Ti-0.1Zr-0.02C alloy. Intermetallics 2011, 19, 541-545. [CrossRef]

6. Majumdar, S. Formation of $\mathrm{MoSi}_{2}$ and $\mathrm{Al}$ doped $\mathrm{MoSi}_{2}$ coatings on molybdenum base TZM (Mo-0.5Ti-0.1Zr-0.02C) alloy. Surf. Coat. Technol. 2012, 206, 3393-3398. [CrossRef]

7. Choi, K.; Yang, W.; Baik, K.H.; Kim, Y.; Lee, S.; Lee, S.; Park, J.S. Growth kinetics and isothermal oxidation behavior of a Si pack cementation-coated Mo-Si-B alloy. Appl. Surf. Sci. 2019, 489, 668-676. [CrossRef]

8. Pu, R.; Sun, Y.; Xu, J.; Zhou, X.; Li, S.; Zhang, B.; Cai, Z.; Liu, S.; Zhao, X.; Xiao, L. Microstructure and properties of Mo-based double-layer $\mathrm{MoSi}_{2}$ thick coating by a new two-step method. Surf. Coat. Technol. 2020, 394, 125840. [CrossRef]

9. Yoon, J.K.; Byun, J.Y.; Kim, G.H.; Kim, J.S.; Choi, C.S. Growth kinetics of three Mo-silicide layers formed by chemical vapor deposition of Si on Mo substrate. Surf. Coat. Technol. 2002, 155, 85-95. [CrossRef]

10. Wang, Q.; Zhang, L.; Zhai, L.L.; Li, J.D.; Zhang, J.W. In-situ synthesis of silicide coatings on molybdenum substrates by electrodeposition in chloride-fluoride molten salts. Int. J. Refract. Met. Hard Mater. 2019, 82, 340-348. [CrossRef]

11. Zhang, Y.; Cui, K.; Fu, T.; Wang, J.; Shen, F.; Zhang, X.; Yu, L. Formation of MoSi2 and Si/MoSi2 coatings on TZM (Mo-0.5Ti0.1Zr-0.02C) alloy by hot dip silicon-plating method. Ceram. Int. 2021, 47, 23053-23065. [CrossRef]

12. Majumdar, S.; Sharma, I.G.; Raveendra, S.; Samajdar, I.; Bhargava, P. In situ chemical vapour co-deposition of Al and Si to form diffusion coatings on TZM. Mater. Sci. Eng. A 2008, 492, 211-217. [CrossRef]

13. Liu, Y.; Shao, G.; Tsakiropoulos, P. Thermodynamic reassessment of the Mo-Si and Al-Mo-Si systems. Intermetallics 2000, 8 , 953-962. [CrossRef]

14. Park, J.; Kim, J.M.; Lee, S.; Park, J.S. Oxidation behaviors of the aluminide coated TZM alloy via pack cementation. Phys. Met. Metallogr. 2014, 115, 1351-1355. [CrossRef]

15. Chakraborty, S.P.; Banerjee, S.; Singh, K.; Sharma, I.G.; Grover, A.K.; Suri, A.K. Studies on the development of protective coating on TZM alloy and its subsequent characterization. J. Mater. Process. Technol. 2008, 207, 240-247. [CrossRef] 
16. Ponweiser, N.; Paschinger, W.; Ritscher, A.; Schuster, J.C.; Richter, K.W. Phase equilibria in the Al-Mo-Si system. Intermetallics 2011, 19, 409-418. [CrossRef]

17. Tamarin, Y. Protective Coatings for Turbine Blades; ASM Int.: Novelty, OH, USA, 2002; p. 300.

18. Bermejo Sanz, J.; Roussel García, R.; Kolarik, V.; del Mar Juez Lorenzo, M. Influence of the Slurry Thickness and Heat Treatment Parameters on the Formation of Aluminium Diffusion Coating. Oxid. Met. 2017, 88, 179-190. [CrossRef]

19. Montero, X.; Galetz, M.C.; Schütze, M. A Novel Type of Environmentally Friendly Slurry Coatings. Jom 2015, 67, 77-86. [CrossRef]

20. Grégoire, B.; Bonnet, G.; Pedraza, F. Mechanisms of formation of slurry aluminide coatings from Al and Cr microparticles. Surf. Coat. Technol. 2019, 359, 323-333. [CrossRef]

21. Kochmańska, A.E. Microstructure of Al-Si Slurry Coatings on Austenitic High-Temperature Creep Resisting Cast Steel. Adv. Mater. Sci. Eng. 2018, 2018, 12. [CrossRef]

22. Jarlaczyńska, A.; Kochmańska, A.; Woitas, A. The structure of silicon coatings obtained on TZM molybdenum alloy by slurry method. Mater. Eng.-Inz. Mater. 2017, 1, 42-47. [CrossRef]

23. Kochmańska, A.E. Microstructure of aluminide coatings on Ti6Al4V alloy produced by the slurry method with inorganic binder. Int. J. Mater. Res. 2018, 109, 735-742. [CrossRef]

24. Kochmańska, A.E. Aluminide coatings on inconel 617 obtained by slurry method with inorganic binder. J. Achiev. Mater. Manuf. Eng. 2017, 85, 49-55. [CrossRef]

25. Tortorici, P.C.; Dayananda, M.A. Growth of silicides and interdiffusion in the Mo-Si system. Metall. Mater. Trans. A 1999, 30, 545-550. [CrossRef]

26. Chakraborty, S.P.; Banerjee, S.; Sharma, I.G.; Suri, A.K. Development of silicide coating over molybdenum based refractory alloy and its characterization. J. Nucl. Mater. 2010, 403, 152-159. [CrossRef]

27. Kochmańska, A. Hot corrosion resistance properties of Al-Si coatings obtained by slurry method. In Defect and Diffusion Forum; Trans Tech Publications Ltd.: Zurich, Switzerland, 2012; pp. 273-278.

28. Prasad, S.; Paul, A. Growth mechanism of phases by interdiffusion and atomic mechanism of diffusion in the molybdenum-silicon system. Intermetallics 2011, 19, 1191-1200. [CrossRef]

29. Tatemoto, K.; Ono, Y.; Suzuki, R.O. Silicide coating on refractory metals in molten salt. J. Phys. Chem. Solids 2005, 66, 526-529. [CrossRef]

30. Zhang, X.Y.; Sprengel, W.; Staab, T.E.M.; Inui, H.; Schaefer, H.-E. Formation of Thermal Vacancies on the Si Sublattice of the Intermetallic Compound MoSi2. Phys. Rev. Lett. 2004, 92, 155502. [CrossRef]

31. Salamon, M.; Strohm, A.; Voss, T.; Laitinen, P.; Riihimäki, I.; Divinski, S.; Frank, W.; Räisänen, J.; Mehrer, H. Self-diffusion of silicon in molybdenum disilicide. Philos. Mag. 2004, 84, 737-756. [CrossRef]

32. Greenwood, N.N.; Earnshaw, A. Chemistry of the Elements, 2nd ed.; Butterworth-Heinemann: Oxford, UK, 1997; ISBN 978-0-08037941-8. 